\title{
REVIEW
}

\section{Epigenetics in breast cancer: what's new?}

\author{
Yi Huang ${ }^{1,2}$, Shweta Nayak ${ }^{3,4}$, Rachel Jankowitz ${ }^{1,3}$, Nancy E Davidson ${ }^{1,2}$ and Steffi Oesterreich,
}

\begin{abstract}
Epigenetic changes are critical for development and progression of cancers, including breast cancer. Significant progress has been made in the basic understanding of how various epigenetic changes such as DNA methylation, histone modification, miRNA expression, and higher order chromatin structure affect gene expression. The present review will focus on methylation and demethylation of histones. While the acetylation of histones has been at the forefront of well-characterized post-translational modifications of histones, including the development of inhibitors targeting de-acetylating enzymes, the past few years have witnessed a dramatic increase in knowledge regarding the role of histone methylation/ demethylation. This is an exciting and rapidly evolving area of research, with much promise for potential clinical intervention in several cancers including breast cancer. We also summarize efforts to identity DNA methylation signatures that could be prognostic and/ or predictive markers in breast cancer, focusing on recent studies using genome-wide approaches. Finally, we briefly review the efforts made by both the National Institutes of Health Epigenome Project and The Cancer Genome Atlas, especially highlighting the study of breast cancer epigenetics, exciting technological advances, potential roadblocks, and future directions.
\end{abstract}

\section{Introduction}

While the term epigenetics is often used loosely, and sometimes in rather different ways, the term is generally considered to encompass changes in DNA methylation, histone modifications, miRNA expression, and nucleosome positioning and higher order chromatin as epigenetic changes affecting gene regulation. Epigenetics was defined as a discipline more than 50 years ago, by $\mathrm{CH}$

\footnotetext{
*Correspondence: oesterreichs@upmc.edu

'University of Pittsburgh Cancer Institute, University of Pittsburgh, Pittsburgh, PA 15232, USA

Full list of author information is available at the end of the article
}

Waddington, and originally described changes in the development of organisms that could not be explained by changes in DNA. Subsequently it became clear that epigenetic modifications play important roles in diseases, including breast cancer. There is thus a pressing need to understand the functional genome; that is, the changes defined by regulatory mechanisms overlaying the genetic structure.

Over the past few years there has been an explosion in studies of epigenetics in breast cancer, reflected by the exponential increase of published manuscripts (Figure 1). A PubMed search for the keywords 'epigenetic' and 'breast cancer' reveals that the first publication was in 1983. Progress was slow until approximately 10 years ago when the number of studies started to steadily increase, at least in part fueled by improved technologies. In the present review, we focus on recent advances in the understanding of histone methylation and demethylation, a relatively new area with promise for clinical translation. We also review recent studies that have utilized genomewide technologies for the study of DNA methylation. Much progress has been made in the characterization of noncoding RNAs, and the effect of higher order chromatin structure on gene expression in breast cancer; however, these discoveries lie outside the scope of our review.

Finally, we also discuss the relatively slow translation of results from the epigenetic field into the clinic. Although there has been a dramatic increase of research into the epigenetics of breast cancer and milestone discoveries have undoubtedly been made, the application of such findings into the clinical setting has been slow. This is in contrast to other areas - for example, profiling of gene expression, where we have witnessed a revolution in the past 4 to 6 years, especially in the translation of the results into the development of US Food and Drug Administration-approved multigene prognostic assays. Why have we not yet seen any predictive/prognostic tests that involve the characterization of epigenetic changes? In a similar way, although a number of drugs targeting epigenetic changes have been tested, at this time no epigenetic drug has received US Food and Drug Administration approval in breast cancer treatment. Is this a result from a slower development of techniques used for epigenetic analysis? Or are there additional 


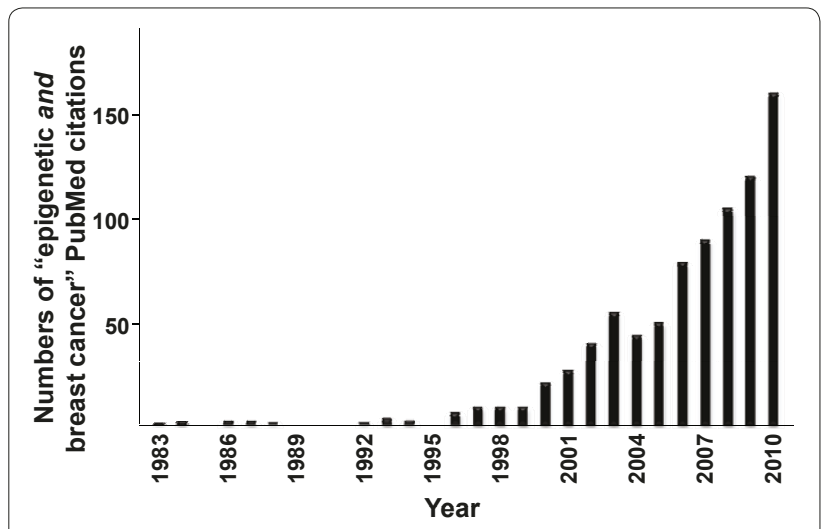

Figure 1. Increased rate of publication in the area of epigenetics and breast cancer. Data are derived from a PubMed citation analysis searching for 'breast cancer' and 'epigenetics', and are approximate reflections of the number of epigenetic studies in the breast cancer area.

obstacles? In the present review article we discuss some barriers to more rapid translation of epigenetic studies in breast tumors into clinical practice, and discuss the efforts by the Epigenome Project and The Cancer Genome Atlas (TCGA) that are expected to bring dramatic progress in the near future.

\section{Acetylation and methylation of histones in breast cancer}

For many years it has been known that post-translational modifications of histone tails determine, in part, which regions of the genome are in an open and thus transcriptionally active conformation, and which are closed and thus transcriptionally inactive. The modifications of histone tails include acetylation, methylation, ubiquitylation, phosphorylation, sumoylation, and ribosylation, each of which can significantly affect the expression of genes [1]. The most studied histone modifications are histone acetylation/deacetylation, and more recently methylation/ demethylation. In breast cancer, abnormal histone modification in combination with DNA hypermethylation is frequently associated with epigenetic silencing of tumor suppressor genes and genomic instability $[2,3]$. Understanding the mechanisms of dysregulation of histone tail post-translational modifications and their contribution to breast tumorigenesis is critically important in the development of novel targeted therapy for breast cancer patients.

\section{Inhibition of histone deacetylases as a therapeutic approach in breast cancer}

The dynamic nature of histone acetylation is determined by the counterbalancing activity of histone acetyltransferases and histone deacetylases (HDACs). The HDAC family is divided into zinc-dependent enzymes (classes I, IIa, IIb, and IV, of which there are 11 subtype enzymes) and zinc-independent enzymes (class III, also called sirtuins), which require $\mathrm{NAD}^{+}$for their catalytic activity [4]. Over the past decade, a number of HDAC inhibitors have been rationally designed and synthesized based on their chemical structures and divided into four groups: hydroxamic acids, cyclic tetrapeptides, short-chain fatty acids, and benzamides [5]. Most of the HDAC inhibitors developed so far are nonselective, and among the most potent inhibitors are those that have been designed to target primarily the zinc cofactor at the active site of the HDACs and to exhibit their effects in the nanomolar or micromolar range [6,7]. Some of these HDAC inhibitors were shown to change the chromatin structure and cause re-expression of aberrantly silenced genes, which in turn is associated with growth inhibition and apoptosis in cancer cells [8,9]. In estrogen receptor (ER)-negative breast cancer cells, inhibition of HDAC activity by specific HDAC inhibitors reactivates ER $\alpha$ and progesterone receptor (PR) gene expression, which are known to be aberrantly silenced [10-14]. Pruitt and colleagues demonstrated that inhibition of class III HDAC SIRT1 using a pharmacologic inhibitor, splitomicin, or siRNA reactivates epigenetically silenced $S F R P 1, S F R P 2$, Ecadherin, and CRBP1 genes in human breast cancer cells [15].

The study of HDAC inhibitors is moving rapidly into a new stage of development that has now started to produce encouraging results in the clinic, particularly in the field of cancer therapy. Vorinostat (SAHA) and romidepsin (FK228) have already been approved by the US Food and Drug Administration for the clinical treatment of cutaneous T-cell lymphoma. Vorinostat is currently under evaluation in several phase II trials in breast cancer $[16,17]$, including combination therapy of vorinostat with standard cytotoxic agents (for example, paclitaxel), endocrine therapy (tamoxifen), or novel targeted therapy (trastuzumab, bevacizumab) [3,16,17]. Other HDAC inhibitors such as MS-275 (entinostat) and LBH-589 (panobinostat) are in phase I/II studies in combination with other agents, such as trastuzumab, in women with metastatic HER2-positive breast cancer [16].

In addition, increasing evidence suggests that combination treatment with inhibitors of HDAC and DNA methyltransferase (DNMT) results in synergy at clinically tolerable doses that may translate not only into changes in methylation but also to disease response. Preclinical studies of HDAC inhibitors in combination with DNMT inhibitors have shown superior re-expression of silenced genes and increased apoptosis in colon/lung cancer cell lines [18], reduced tumorigenesis in lung cancer models $[19,20]$, superior ER re-expression compared with HDAC inhibitor alone in breast cancer cell lines [12], and restoration 
of tamoxifen responsiveness [13,21]. In a phase I clinical trial of phenylbutyrate in combination with the DNMT inhibitor 5-azacitidine in myelodysplasia, response was highly correlated with reversal of aberrantly methylated genes [22]. In another phase I trial in nonsmall-cell lung cancer, the combination of a DNMT inhibitor and an HDAC inhibitor was safe and tolerable, and was associated with clinical activity [23].

An ongoing phase II trial is testing the HDAC inhibitor entinostat (also known as SNDX-275 and MS-275), in combination with 5 -azacitidine, in patients with hormonerefractory or triple-negative metastatic breast cancer. The primary endpoint will be the objective response rate; secondary endpoints will be progression-free survival, overall survival, and clinical benefit rate, as well as safety and tolerability. Other analyses will include the pharmacokinetics of 5-azacitidine and entinostat, cytidine deaminase activity, pharmacogenetics, and baseline and change in gene methylation in circulating DNA prior to/ following combination therapy (quantitative multiplex methylation specific PCR). The study will also aim to evaluate baseline and change in malignant tissue via mandatory biopsies prior to/following combination therapy of gene methylation of candidate genes (by quantitative methylation specific PCR) and of genomewide methylome, coupled with the study of candidate gene re-expression (RT-PCR). We are at a critical turning point, because results from these critical studies will guide future trials with HDAC inhibitors.

\section{Targeting histone lysine methylation and demethylation in breast cancer}

Histone lysine methylation is a reversible process, dynamically regulated by both lysine methyltransferases and demethylases (Figure 2). In general, methylation of histone $\mathrm{H} 3$ lysine 4 (H3K4me), H3K36, or H3K79 is associated with active transcription, whereas methylation of H3K9, H3K27, or H4K2O is associated with gene silencing [1]. Histone methylation is regulated in breast cancer in an even more complicated manner than histone acetylation via a large number of chromosomal remodeling regulatory complexes.

Modification of H3K4 methylation is catalyzed by the Trithorax group of histone methyltransferases, including SET1 and MLL [24]. The activity of Trithorax proteins is balanced by the opposing effects of the Polycomb group factors, another important histone methyltransferase family that mediates methylation usually associated with epigenetic gene silencing [25]. Polycomb group proteins form at least four different complexes, including the maintenance complex PRC1 - composed of RING, HPC, $\mathrm{HPH}$, and BMI1 - and three different initiation complexes, PRC2 through PRC4, which are formed by core component of zeste homolog 2 (EZH2), suppressor of zeste 12 (SUZ12), and Nurf-55 [26,27]. EZH2 is a highly conserved histone methyltransferase that specifically targets $\mathrm{H} 3 \mathrm{~K} 27$ and functions as transcriptional repressor [28]. Tissue microarray analysis of breast cancers identified consistent overexpression of EZH2, which was strongly associated with tumor aggressiveness [29]. Studies from several groups demonstrated that expression of EZH2 is significantly associated with increased proliferation and other features of aggressive breast cancer, such as p53 alterations, c-erbB-2 expression, markers of the basal-like subtype, and glomeruloid microvascular proliferation [30,31]. Finally, in a recent report by Chang and colleagues, EZH2 was shown to repress DNA repair in breast-tumor-initiating cells, potentially leading to expansion of stem-cell-like cells, and finally to breast cancer progression [32]. Collectively, these results suggest that EZH2 might function as a prognostic biomarker in breast cancer, and might also be a promising treatment target.

Histone lysine-specific demethylase 1 (LSD1, also known as BHC110, AOF2, or KDM1) is the first identified histone lysine demethylase capable of specifically demethylating monoethylated and dimethylated lysine 4 of histone H3 (H3K4me1 and H3K4me2) [33,34]. The discovery of LSD1 has revolutionized the concept of histone methylation as a dynamically regulated process under enzymatic control, rather than chromatin marks that could only be changed by histone replacement. The activity of the LSD1-CoREST-HDAC complex has been implicated in tumorigenesis. A recent study using ELISA determined that LSD1 is highly expressed in ER-negative breast tumors, and hence LSD1 was suggested to serve as a predictive marker for aggressive breast tumor biology and a novel attractive therapeutic target for treatment of ER-negative breast cancers [35]. In ER-positive human breast cancer MCF-7 cells, $42 \%$ and $58 \%$ of all Pol II and ER $\alpha$-bound promoters, respectively, were found to be bound by LSD1, and the recruitment of LSD1 to the promoters of $\mathrm{LSD} 1^{+} / \mathrm{ER} \alpha^{+}$target genes was stimulated by estradiol [36].

Intriguingly, Perillo and colleagues reported that LSD1mediated demethylation produces $\mathrm{H}_{2} \mathrm{O}_{2}$, which subsequently modifies the surrounding DNA and recruits 8-oxoguanine-DNA glycosylase 1 and topoisomerase II $\beta$, triggering conformational changes in DNA and chromatin that are essential for estrogen-induced transcription [37]. Our recent study demonstrated that LSD1 interacts closely with HDACs in human breast cancer cells. Importantly, inhibitors of histone demethylation and deacetylation exhibit cooperation and synergy in regulating gene expression and growth inhibition, and may represent a promising and novel approach for epigenetic therapy of breast cancer [38]. Recent studies also revealed that LSD1 is able to demethylate nonhistone substrates 


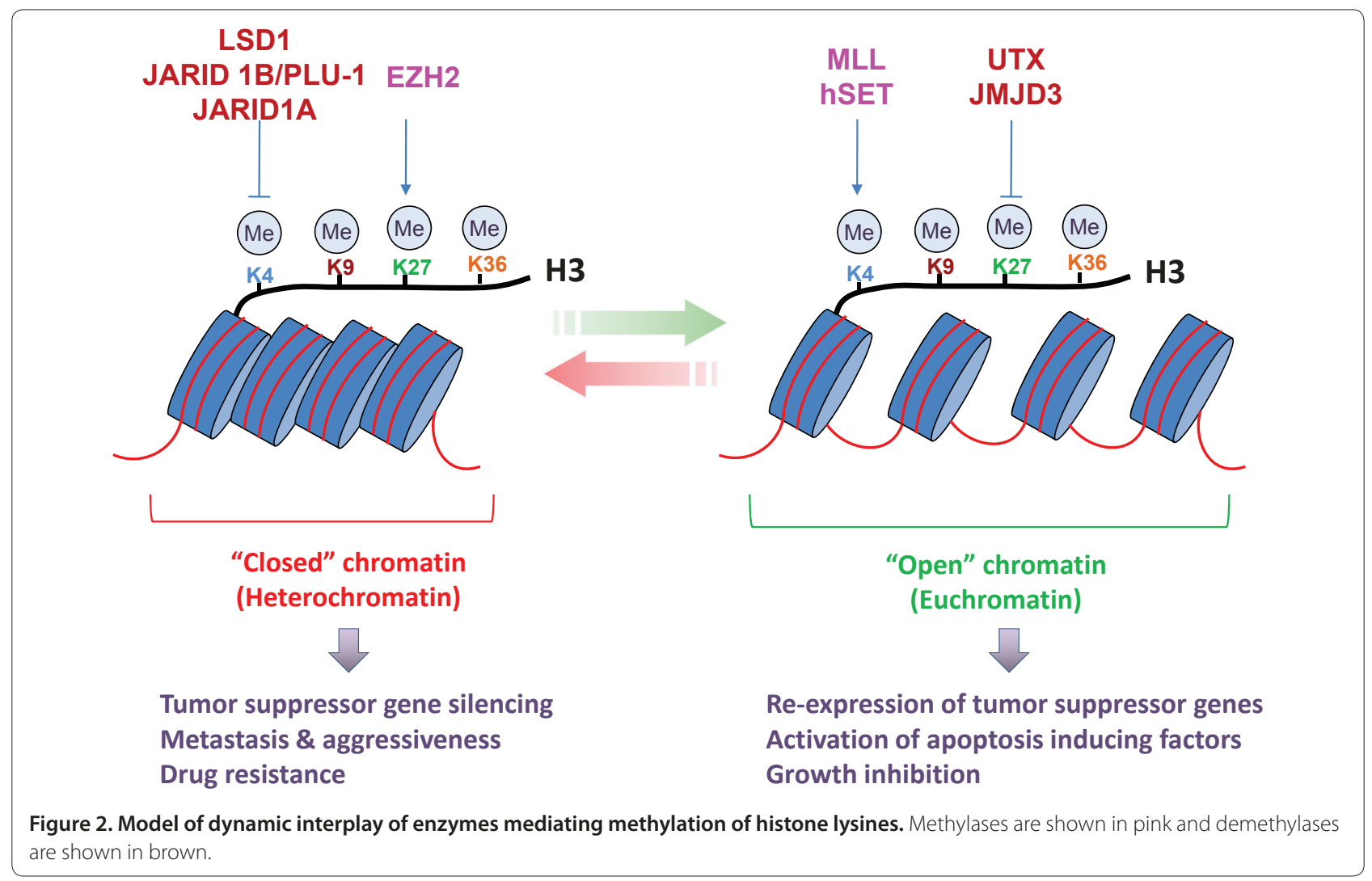

such as p53 and DNMT1, indicating broader biological functions for LSD1 $[39,40]$.

Subsequent to the discovery of LSD1, other Jumonji C (JmjC) domain-containing proteins were proposed to function as human histone demethylases. These enzymes use $\alpha$-ketoglutarate and iron as cofactors to demethylate histone lysine residues through a hydroxylation reaction [41-44]. Little is known about the role of JmjC domaincontaining histone demethylase in breast cancer, but recent studies found that PLU-1 (also known as JARID1B or KDM5B) contributes to MCF-7 cell proliferation by facilitating $G_{1}$ progression. Further, knockdown of PLU-1 led to a significant reduction of MCF-7 cell proliferation and upregulation of expression of certain tumor suppressor genes, including 14-3-3 $\sigma$, BRCA1, CAV1, and HOXA5 [45]. Sharma and colleagues reported that the development of drug-tolerant cancer cells was at least in part mediated by activities of the histone demethylase JARID1A/KDM5A. While these studies focused on epidermal growth factor receptor-targeting small-molecule inhibitors in lung cancer cells, the authors showed that a similar mechanism for resistance existed for other therapies, such as cis-platin. One could thus rationalize that activation of this pathway might be a more widespread phenomenon for the development of drug resistance in JARID1A/KDM5A-expressing tumors $[46,47]$.

\section{Emerging therapeutic potential of histone methyltransferase and demethylase inhibitors in breast cancer}

As depicted in Figure 2, histone methylation is the result of a dynamic equilibrium between activities of a number of histone methyltransferases and demethylases. Given the increasing evidence for their role in tumorigenesis, it is no surprise they are being developed and tested as novel treatment targets.

Enhanced activity of histone-modifying enzymes such as LSD1 and EZH2 leads to epigenetic silencing of critical genes, such as tumor suppressor genes, that have been shown to play an important role in breast tumor tumorigenesis. A series of novel compounds function as powerful inhibitors of histone methylation or demethylation and are capable of inducing re-expression of aberrantly silenced genes important in breast tumorigenesis. A list of identified histone methyltransferase and demethylase inhibitors is presented in Table 1. One of the first histone methyltransferase inhibitors developed is chaetocin, which exhibits some selectivity for the SUV39 class of histone methyltransferases [48]. The EZH2 inhibitor DZNep induces robust apoptosis in breast cancer cells, at least in part by including a novel apoptosis effector, FBXO32 [49]. SMYD3 is a H3K4-specific methyltransferase that is frequently overexpressed in a 
Table 1. Characteristics of some histone methyltransferase and demethylase inhibitors

\begin{tabular}{lccc}
\hline Inhibitor & Major targeted enzymes & Changed histone marks & Citation \\
\hline Chaetocin1 & Suv39h1, G9a & H3K9 & {$[48]$} \\
DZNep & EZh2 & H3K27 & {$[49]$} \\
Novobiocin & SMYD3 & H3K4 & {$[51]$} \\
Trancylpromine, clorgyline, pargyline & LSD1, LSD2 & H3K4, H3K9 & {$[35,52,53]$} \\
Polyamine analogs & LSD1 & H3K4 & {$[54,55]$} \\
$N$-oxalylglycine & JMJD2A, JMJD2C & H3K9, H3K36 & {$[57]$} \\
\hline
\end{tabular}

variety of cancers, including breast cancer [50]. Novobiocin, known as a HSP90 inhibitor, decreases the expression of SMYD3 and inhibits the proliferation and migration of MDA-MB-231 cells in a dose-dependent fashion [51].

The structural and catalytic similarities of LSD1 and monoamine oxidase or polyamine oxidase provided the rationale to investigate whether existing monoamine oxidases or polyamine oxidase inhibitors might also act as inhibitors of LSD1. Subsequently, the monoamine oxidase inhibitors tranylcypromine, clorgyline, and pargyline were shown to inhibit LSD1 activity and inhibit growth of breast cancer and prostate cancer cells $[35,52,53]$. Interestingly, pargyline (Eutonyl; SigmaAldrich, St Louis, MO, USA) has already been clinically used for the treatment of vascular hypertension, and tranylcypromine (Parnate; Sigma-Aldrich, St Louis, MO, USA) is a drug used as an antidepressant and anxiolytic agent in the clinical treatment of mood and anxiety disorders. Unless there are toxicities due to the high doses that might be required to inhibit LSD1, one might expect this drug to be tested in the cancer arena soon.

More recently, polyamine-based LSD1 inhibitors were identified and demonstrated to reactivate epigeneticsilenced tumor suppressor genes in cancer cells $[54,55]$. Treatment with the LSD1-inhibiting polyamine analogues 2d or PG-11144 significantly enhanced global $\mathrm{H} 3 \mathrm{~K} 4 \mathrm{me} 2$ and altered gene expression in breast cancer MDA-MB-231 cells [56]. Treatment with the LSD1 inhibitor PG-11144 and the DNMT inhibitor 5-aza-2deoxycytidine resulted in significant inhibition of the growth of established tumors in a xenograft model of human colon cancer in nude mice [55]. $N$-oxalylglycine, an analog of $\alpha$-ketoglutarate, has been shown to be an inhibitor of the $\mathrm{JmjC}$ domain-containing histone demethylases JMJD2A and JMJD2C [57]. These advances show the promise of using novel compounds that target the histone methylation/demethylation pathway as an innovative approach to breast cancer treatment, and are anticipated to lead to the development of a new generation of therapeutically effective epigenetically-active drugs with considerable clinical potential.

\section{The DNA epigenome in breast cancer}

\section{Single-marker studies in breast cancer}

Over the past decade, significant progress has been made in the identification and characterization of altered DNA methylation in breast cancer development and progression. A number of genes have been consistently reported to be methylated, including RASSF1A, ER $\alpha, P R, R A R \beta$, CCND2, and PITX2. We will not review these findings here, but would like to point the interested reader towards a number of comprehensive reviews on this topic $[20,58,59]$. The other frequently hypermethylated gene with a tumor-specific methylation profile is $B R C A 1$ $[60,61]$. Although it has become clear that inactivation of $B R C A 1$ by epigenetic means is a critical event in breast (and ovarian) tumorigenesis, differences in experimental approaches and also in the region of the BRCA1 promoter analyzed resulted in ranges of methylation, and thus warrant some further analysis. In any case, in the present review we will focus on results from some recent genome-wide methylation studies in breast cancer.

\section{Analysis of the breast cancer epigenome using genome- wide approaches}

Unprecedented advances have been made in the development of techniques to study genome-wide DNA methylation. Briefly, there are currently four major approaches to identify 5-methylcytosine: restriction endonucleasebased analysis, bisulfite-conversion of DNA, affinity and immunoprecipitation-based studies (methyl Cp6 binding domain (MBD) pulldown, or antibodies against 5-methylcytosine in DNA or against proteins binding to 5-methylcytosine, such as MBD2 and MeCP2), and finally mass spectrometry-based analysis. Most of the approaches have been adapted to be used for genomewide studies using array-based or sequencing-based methods, and some have been utilized to study methylation of the breast cancer genome, as discussed below.

In 2007 Ordway and colleagues used cytosine methylation-dependent restriction enzyme McrBC coupled with array hybridization to analyze methylation in nine matched invasive ductal carcinoma and adjacent normal tissue [62]. They identified 220 differentially methylated 
loci, and analyzed 16 genes that were able to differentiate breast tumor from normal and benign tissues and blood in more detail. One of these genes was GHSR, a member of the G-protein-coupled receptor that binds to ghrelin. Methylation of GHSR was able to differentiate invasive ductal carcinoma from normal or benign breast tissue with high specificity and sensitivity. The same group went on to study four of the highly methylated loci - GHSR, max gene-associated, nuclear factor I/X, and an unannotated region on chromosome 7 - in more detail through bisulfite pyrosequencing using DNA from breast tumors, normal breast, and sera from cancer patients and from normal controls. Disappointingly, no tumor-specific methylation pattern could be identified, and high methylation rates were detected in normal sera [63]. The latter would clearly pose a problem for the development of sera-based assays and highlights the need to identify markers that are not methylated in normal serum.

Ruike and colleagues reported results from a genomewide methylated DNA immunoprecipitation-sequencing study in breast cancer cells [64]. Briefly, they identified methylated DNA in eight breast cancer cell lines and one normal breast cell line, and in addition they compared methylation rates between parental MCF-7 cells and MCF-7 cells that had undergone epithelial to mesenchymal transition. As expected, the cancer cell lines were characterized by global hypomethylation, concurrent with hypermethylation of many loci. The hypomethylation, which was distributed throughout the entire genome, was three to five times more frequent than hypermethylation, which was clustered at specific loci. Intriguingly, 53\% of methylated CpG was found outside CpG islands. Of interest was also the association of epithelial to mesenchymal transition with hypomethylation at many $\mathrm{CpG}$ islands, a finding that deserves follow-up.

It will be of great value to apply these approaches to answer clinical questions, such as the association of genome-wide changes in DNA methylation with different grades or stages of breast tumor. A recent genome-wide study by Fang and colleagues [65] has suggested that a CpG island methylator phenotype (CIMP) exists in breast cancer. This breast cancer CIMP provided a distinct epigenomic profile, which was associated with genes that make up the metastasis transcriptome. Additional studies need to be performed before one can confidently state that there are CIMP tumors associated with specific tumor phenotypes. Another interesting question is the association between methylation and molecular subtypes of breast tumors.

A recent study by Holm and colleagues suggests that luminal tumors have higher frequencies of methylation compared with basal or triple-negative breast tumors
[58]. Briefly, the authors studied 189 frozen primary breast tumors using the Illumina Golden Gate Methylation Cancer Panel, covering 1,505 CpG loci in 807 cancer-related genes. Unsupervised clustering revealed that methylation patterns were associated with luminal A, luminal B, and basal-like tumors, with luminal B tumors being most methylated and basal-like tumors being the least methylated. As previously reported, Her-2 tumors are very heterogeneous and are mainly driven by amplification of Her-2 as the common denominator. High expression of PRC2 and low methylation of known PRC2 targets in basal-like tumors suggest that PRC2 targets might be silenced by trimethylation of H3K27 in this tumor subset. In general, these data clearly suggest that methylation plays a significant role in the different breast tumor subsets, and it will be critical to determine the mechanism that drives different methylation states. The authors speculate a role for genetic changes in methylation enzymes, an interesting hypothesis that is testable.

Lineage-specific methylation was also observed in a methylation study performed by Sproul and colleagues [66], who used 27K Infinium arrays to study the methylation at $>14,000$ genes in 19 breast cancer cell lines and 47 primary tumors. The authors bring forward the argument that DNA methylation in breast tumors is a marker of cell lineage rather than tumor progression. This study again emphasizes the need to identify tumor-specific methylation events, a task most critical for the future use of DNA methylation for diagnosis and treatment of breast cancer.

Another clinical question is the involvement of DNA methylation in the adaptation of cancer cells to treatment exposure. We recently performed an MBD-pulldown assay in breast cancer cells deprived of estrogen, thus mimicking treatment with aromatase inhibitors. This approach resulted in the identification of a large number of hypermethylated genes, and fewer that were hypomethylated (Pathiraja and colleagues, manuscript in preparation). It will be of great interest to expand those studies to clinical samples, in order to identify markers of resistance, and potential drug targets.

Clearly, these studies are only the beginning for the use of genome-wide methylation studies. With the advent of improved technologies, we should expect to witness an explosion of studies aimed at understanding epigenetic changes in breast cancer. This not only refers to DNA methylation, but also to other epigenetic changes, such as histone modification, which can now also be studied genome wide through the use of chromatin immunoprecipitation technologies At least in part, these efforts should soon benefit from the results of the Human Epigenome Project and TCGA, as briefly discussed below. 


\section{Epigenome Project and TCGA: their role in understanding epigenetics of breast cancer (and other diseases) \\ Description of Epigenome Roadmap initiatives}

The Epigenome Project is a Roadmap initiative led by several National Institutes of Health (NIH) centers, started in 2008 when the NIH decided to invest over $\$ 190$ million to accelerate the advancement of biomedical research in epigenomics. A series of five initiatives was therefore created. The first initiative is the creation of reference epigenome mapping centers, which support the development of reference epigenomes of a variety of human cells, including normal breast epithelial cells. The data gathered include information on DNA methylation, histone modifications, and associated noncoding RNAs. The second initiative focuses not only on coordinating the banking of data, but also on facilitating its access to the public, accomplished through the creation of the Epigenomic Data Analysis and Coordination center. The third initiative seeks to advance technology in epigenetic research, by enabling the development of new techniques, including the creation of methods that allow in vivo imaging of epigenetic changes. The objective of the fourth initiative is to identify epigenetic marks and establish their function in mammalian cells. Finally, the intention of the fifth initiative is to identify those epigenetic changes that are the cause of specific diseases, including breast cancer.

Importantly, the NIH roadmap initiative is part of an international association, the International Human Epigenome Consortium, which has made several recommendations with regard to data release, format, and various technical considerations, in order to universalize and validate findings [67]. Regarding the former, it is recommended that all data be made available through one of several public databases, such as GEO, ARRAYEXPRESS, and DDBJ.

Funded roadmap initiatives have resulted in many fundamental contributions, including a study published late in 2009 that presented the first genome-wide, singlebase resolution map of methylated cytosines in the mammalian genome from both human embryonic stem cells and fetal fibroblasts [68]. Importantly, almost onequarter of all methylation identified in stem cells was in a non-CpG context, a finding that does not seem to be restricted to methylation in stem cells. Subsequently, an approach was developed to sequence chromatin-immunoprecipitated DNA from limited cell populations, an approach most critical for working with clinical samples [69]. A study by Ernst and Kellis described a multivariate Hidden Markov Model to reveal chromatin states in human $\mathrm{T}$ cells through the systematic analysis of 51 chromatin states, including promoter-associated states, transcription-associated states, active intergenic states, large-scale repressed states, and repeat-associated states [70].

Finally, two studies have explored the strengths and weaknesses of four methods of DNA methylation mapping technologies, while providing recommendations on the design of case-control studies in epigenomics $[71,72]$. These studies mark a critical milestone for the Human Epigenome Project, since the development of genome-wide technology has been a major focus on the initiative. Briefly, six methods were tested, of which five were sequence-based and one was array-based. Each method was subjected to rigorous testing, and to statistical analysis of at least two replicate samples. Although resolution and coverage differed, there was high concordance between the different methods, providing a high level of confidence for all epigenetic researchers, and providing flexibility as to which methods to choose based on the need for resolution, the amount of available starting material, and, last but not least, the budget.

\section{NIH Roadmap studies deciphering the breast cancer epigenome}

The initiative also funded disease-specific studies, including those in breast cancer. One such study is the analysis of special AT-rich sequence binding 1 (SATB1) in metastatic breast cancer. The Kohwi-Shigematsu laboratory identified SATB1, originally described as a genome organizer in thymocytes [73-75], to be a key determinant in breast cancer metastasis [76].

While there is some controversy about the detailed function of SATB1 in breast cancer [77], there is no doubt that SATB1 functions as a critical, global, genome organizer by recognizing and binding to specialized DNA sequences in the genome that have a high propensity to unwind (base-unpairing regions). SATB1 organizes chromatin into loops through binding of base-unpairing regions, which are found in gene-rich regions, and can regulate a large number of distally located genes by functioning as a landing platform for multiple chromatin remodeling/modifying proteins that confer specific epigenetic marks [78]. In breast cancer, once SATB1 becomes expressed, it regulates $\sim 1,000$ genes, including those involved in cancer progression, metastasis, and growth (for example, ERBB2, transforming growth factor beta).

The Kohwi-Shigematsu group is currently using genome-wide approaches to map all base-unpairing regions in the genome and to determine which particular subset of these is bound by SATB1, and whether these specific epigenomic modifications are associated with poor-prognosis expression profiles of aggressive breast cancers. In addition, using a new approach of analyzing three-dimensional gene interactions, they have found 
that the $c-M Y C$ gene locus is frequently brought into close proximity with a multitude of genes related to myc or co-amplified in cancer. Forced SATB1 expression in nonaggressive breast cancer cells led to a major change in c- $M Y C$ interaction pattern, establishing new connections with genes, some of which are related to cancer ( $\mathrm{T}$ Kohwi-Shigematsu, personal communication). This study provides a concrete example of how the Epigenome Project supports the understanding of the progression from nonaggressive breast cancer to metastatic cancer by establishing genome-wide changes in epigenetic marks, at least in part through global reorganization of higher order chromatin structures by proteins such as SATB1 and others. The critical role for chromatin-organizing proteins is reflected by frequent mutations, such as the recently described mutation of ARID1A in ovarian cancer [47] and other cancers [79].

In addition, beginning in October 2010, the Epigenome Project began to release data that included more than 300 maps of epigenetic changes in over 56 cell and tissue types, including a number of normal breast cells [80]. For example, one can access data on DNA methylation as well as a number of critical genome-wide histone markers (for example, methylation at lysines K4, K9, K27, and K36). These data should help to define breast cancerspecific changes, by allowing researchers to compare the breast cancer data with the normal reference epigenome. This, however, brings up one of several hurdles the project must overcome. There are challenges regarding data integration, interpretation, and dissemination - as one would expect given that the technologies used are all relatively new. There is a critical need for the creation of a new generation of tools for interpretation of the numerous epigenetic datasets [81]. Briefly, in contrast to DNA sequence data, epigenomic data are not digital, differ in resolution, and are highly variable. These features make comparisons of epigenomes challenging, and require sophisticated informatics tools often not easily accessible for just any general laboratory. Increasing accumulation of data, coupled with improved data and tool integration, and access to computing resources and services, preferably through well-established and proven pipelines, are necessary for the efficient and successful analysis of the unprecedented increase of epigenetic information.

\section{Epigenetic studies in breast cancer as part of The Cancer Genome Atlas}

TCGA began in 2006 as a combined effort by the National Cancer Institute and the National Human Genome Research Institute. The success of the three-year pilot project led the NIH to commit major resources to TCGA to collect and characterize more than 20 tumor types, including breast cancer. Tumor DNA and RNA will be thoroughly characterized using a number of approaches. Data are currently available for the brain tumor glioblastoma multiforme (GBM) and ovarian cancer, and we can expect more completion of the breast cancer studies by the end of this year.

Currently, epigenomics studies within TCGA use the HumanMethylation27 BeadChip (Illumina, San Diego, CA, USA). This assay allows quantitative interrogation of 27,578 CpG loci covering more than 14,000 genes at single-nucleotide resolution. Specifically, the panel targets CpG sites located within the proximal promoter regions of 14,475 consensus coding sequences, and in 110 miRNA promoters. As of April 2011 these data have been available from the TCGA data portal for more than 400 breast cancers [82], and we can look forward to the report of its first analysis. Of note, a similar TCGAdirected approach in GBM resulted in the identification of a unique glioma CIMP in about $10 \%$ of patients, who are usually very young at the time of diagnosis. These patients survive more than 3 years, which is in stark contrast to most GBM patients who survive fewer than 15 months. Interestingly, the study also revealed an association between glioma CIMP with an acquired mutation in the IDH1 gene.

The development of these technologies is moving very rapidly, and just when we thought we had a battery of gold standards for genome-wide analysis of DNA methylation it becomes clear that additional modifications such as hydroxymethyl cytosines, and methylated cytosines outside $\mathrm{mCpG}$ islands and outside promoter regions, are likely to play critical roles, including in breast cancer. One may have speculated that the sole analysis of promoter methylation - as done in the TCGA studies might miss cancer-specific changes in other critical regulatory regions. The exciting findings from the GBM study, however, clearly show that promoter methylation includes clinically significant information, and we should look forward to additional data and analyses from the breast cancer TCGA studies.

\section{Conclusions}

While an understanding of epigenetic changes in breast cancer has yet to be translated into clinical care, we should expect major steps forward over the next few years. Fundamental discoveries in the understanding of basic epigenetic regulatory mechanisms and dramatic advances in powerful technologies, together with large national and international epigenome projects, will enable identification of breast cancer-specific alterations, and thus potential predictive markers and treatment targets. We firmly believe we have entered an era of epigenomics that will bring benefits for breast cancer patients. 


\section{Abbreviations}

CIMP, CpG island methylator phenotype; DNMT, DNA methyltransferase: ELISA, enzyme-linked immunosorbent assay; ER, estrogen receptor; EZH2, zeste homolog 2; GBM, glioblastoma multiforme; HDAC, histone deacetylase; JmjC, Jumonji C; LSD1, lysine-specific demethylase 1; miRNA, microRNA; $\mathrm{NIH}$, National Institutes of Health; PCR, polymerase chain reaction; RT, reverse transcriptase; $S A T B 1$, special AT-rich sequence binding 1; siRNA, small interfering RNA; TGCA, The Cancer Genome Atlas.

\section{Competing interests}

The authors declare that they have no competing interests.

\section{Author details}

'University of Pittsburgh Cancer Institute, University of Pittsburgh, Pittsburgh PA 15232, USA. ${ }^{2}$ Department of Pharmacology \& Chemical Biology, University of Pittsburgh, Pittsburgh, PA 15232, USA. ${ }^{3}$ Women's Cancer Research Center, University of Pittsburgh, Pittsburgh, PA 15232, USA. ${ }^{4}$ Department of Medicine, University of Pittsburgh, Pittsburgh, PA 15232, USA.

Published: 1 November 2011

\section{References}

1. Jenuwein T, Allis CD: Translating the histone code. Science 2001, 293:1074-1080.

2. Jones PA, Baylin SB: The epigenomics of cancer. Cell 2007, 128:683-692.

3. Stearns V, Zhou Q, Davidson NE: Epigenetic regulation as a new target for breast cancer therapy. Cancer Invest 2007, 25:659-665.

4. Minucci S, Pelicci PG: Histone deacetylase inhibitors and the promise of epigenetic (and more) treatments for cancer. Nat Rev Cancer 2006, 6:38-51.

5. Dokmanovic M, Marks PA: Prospects: histone deacetylase inhibitors. J Cell Biochem 2005, 96:293-304.

6. Marks PA, Richon VM, Miller T, Kelly WK: Histone deacetylase inhibitors. Adv Cancer Res 2004, 91:137-168.

7. Ficner R: Novel structural insights into class I and II histone deacetylases. Curr Top Med Chem 2009, 9:235-240.

8. Marson CM: Histone deacetylase inhibitors: design, structure-activity relationships and therapeutic implications for cancer. Anticancer Agents Med Chem 2009, 9:661-692

9. Khan O, La Thangue NB: Drug Insight: histone deacetylase inhibitor-based therapies for cutaneous T-cell lymphomas. Nat Clin Pract Oncol 2008, 5:714-726.

10. Keen JC, Yan L, Mack KM, Pettit C, Smith D, Sharma D, Davidson NE: A novel histone deacetylase inhibitor, scriptaid, enhances expression of functional estrogen receptor alpha (ER) in ER negative human breast cancer cells in combination with 5-aza 2'-deoxycytidine. Breast Cancer Res Treat 2003, 81:177-186

11. Zhou Q, Atadja P, Davidson NE: Histone deacetylase inhibitor LBH589 reactivates silenced estrogen receptor alpha (ER) gene expression without loss of DNA hypermethylation. Cancer Biol Ther 2007, 6:64-69.

12. Yang X, Ferguson AT, Nass SJ, Phillips DL, Butash KA, Wang SM, Herman JG, Davidson NE: Transcriptional activation of estrogen receptor alpha in human breast cancer cells by histone deacetylase inhibition. Cancer Res 2000, 60:6890-6894

13. Sharma D, Saxena NK, Davidson NE, Vertino PM: Restoration of tamoxifen sensitivity in estrogen receptor-negative breast cancer cells: tamoxifenbound reactivated ER recruits distinctive corepressor complexes. Cancer Res 2006, 66:6370-6378.

14. Pathiraja TN, Shetty TB, Jelinek J, He R, Hartmaier R, Margossian AL, Hilsenbeck SG, Issa JP, Oesterreich S: Progesterone receptor isoform-specific promoter methylation - Association of PRA methylation with worse outcome in breast cancer patients. Clin Cancer Res 2011, 17:4177-4186.

15. Pruitt K, Zinn RL, Ohm JE, McGarvey KM, Kang SH, Watkins DN, Herman JG, Baylin SB: Inhibition of SIRT1 reactivates silenced cancer genes without loss of promoter DNA hypermethylation. PLOS Genet 2006, 2:e40.

16. ClinicalTrials.gov [http://clinicaltrials.gov]

17. Pathiraja TN, Stearns $V$, Oesterreich S: Epigenetic regulation in estrogen receptor positive breast cancer - role in treatment response. J Mammary Gland Biol Neoplasia 2010, 15:35-47.

18. Cameron EE, Bachman KE, Myohanen S, Herman JG, Baylin SB: Synergy of demethylation and histone deacetylase inhibition in the re-expression of genes silenced in cancer. Nat Genet 1999, 21:103-107.
19. Belinsky SA, Klinge DM, Stidley CA, Issa JP, Herman JG, March TH, Baylin SB: Inhibition of DNA methylation and histone deacetylation prevents murine lung cancer. Cancer Res 2003, 63:7089-7093.

20. Belinsky SA, Grimes MJ, Picchi MA, Mitchell HD, Stidley CA, Tesfaigzi Y, Channell MM, Liu Y, Casero RA Jr, Baylin SB, Reed MD, Tellez CS, March TH: Combination therapy with vidaza and entinostat suppresses tumor growth and reprograms the epigenome in an orthotopic lung cancer model. Cancer Res 2011, 71:454-462.

21. Fan J, Yin WJ, Lu JS, Wang L, Wu J, Wu FY, Di GH, Shen ZZ, Shao ZM: ER alpha negative breast cancer cells restore response to endocrine therapy by combination treatment with both HDAC inhibitor and DNMT inhibitor. $J$ Cancer Res Clin Oncol 2008, 134:883-890.

22. Gore SD: Six (or more) drugs in search of a mechanism: DNA methyltransferase and histone deacetylase inhibitors in the treatment of myelodysplastic syndromes. J Natl Compr Canc Netw 2006, 4:83-90.

23. Juergens RA, Vendetti F, Coleman B, Sebree RS, Rudek MA, Belinsky SA, Brock MV, Herman JG, Baylin SB, Rudin CM: Phase I trial of 5-azacitidine (5AC) and SNDX-275 in advanced lung cancer (NSCLC). J Clin Oncol 2008, 26 (May 20 suppl):abstract 19036.

24. Martin C, Zhang Y: The diverse functions of histone lysine methylation. Nat Rev Mol Cell Biol 2005, 6:838-849.

25. Schuettengruber B, Chourrout D, Vervoort M, Leblanc B, Cavalli G: Genome regulation by polycomb and trithorax proteins. Cell 2007, 128:735-745.

26. Baylin S, Ohm J: Epigenetic gene silencing in cancer - a mechanism for early oncogenic pathway addiction? Nat Rev Cancer 2006, 6:107-116

27. Kuzmichev A, Margueron R, Vaquero A, Preissner TS, Scher M, Kirmizis A, Ouyang X, Brockdorff N, Abate-Shen C, Farnham P, Reinberg D: Composition and histone substrates of polycomb repressive group complexes change during cellular differentiation. Proc Natl Acad Sci U S A 2005, 102:1859-1864.

28. van der Vlag J, Otte AP: Transcriptional repression mediated by the human polycomb-group protein EED involves histone deacetylation. Nat Genet 1999, 23:474-478.

29. Kleer CG, Cao Q, Varambally S, Shen R, Ota I, Tomlins SA, Ghosh D, Sewalt RG, Otte AP, Hayes DF, Sabel MS, Livant D, Weiss SJ, Rubin MA, Chinnaiyan AM: $\mathrm{EZH} 2$ is a marker of aggressive breast cancer and promotes neoplastic transformation of breast epithelial cells. Proc Natl Acad Sci U S A 2003, 100:11606-11611.

30. Collett K, Eide GE, Arnes J, Stefansson IM, Eide J, Braaten A, Aas T, Otte AP, Akslen LA: Expression of enhancer of zeste homologue 2 is significantly associated with increased tumor cell proliferation and is a marker of aggressive breast cancer. Clin Cancer Res 2006, 12:1168-1174.

31. Bachmann IM, Halvorsen OJ, Collett K, Stefansson IM, Straume O, Haukaas SA Salvesen HB, Otte AP, Akslen LA: EZH2 expression is associated with high proliferation rate and aggressive tumor subgroups in cutaneous melanoma and cancers of the endometrium, prostate, and breast. J Clin Oncol 2006, 24:268-273.

32. Chang CJ, Yang JY, Xia W, Chen CT, Xie X, Chao CH, Woodward WA, Hsu JM, Hortobagyi GN, Hung MC: EZH2 promotes expansion of breast tumor initiating cells through activation of RAF1-beta-catenin signaling. Cancer Cell 2011, 19:86-100.

33. Shi Y, Lan F, Matson C, Mulligan P, Whetstine JR, Cole PA, Casero RA: Histone demethylation mediated by the nuclear amine oxidase homolog LSD1. Cell 2004, 119:941-953.

34. Lee MG, Wynder C, Cooch N, Shiekhattar R: An essential role for CoREST in nucleosomal histone 3 lysine 4 demethylation. Nature 2005, 437:432-435.

35. Lim S, Janzer A, Becker A, Zimmer A, Schule R, Buettner R, Kirfel J: Lysinespecific demethylase 1 (LSD1) is highly expressed in ER-negative breast cancers and a biomarker predicting aggressive biology. Carcinogenesis 2010, 31:512-520.

36. Garcia-Bassets I, Kwon YS, Telese F, Prefontaine GG, Hutt KR, Cheng CS, Ju BG, Ohgi KA, Wang J, Escoubet-Lozach L, Rose DW, Glass CK, Fu XD, Rosenfeld MG: Histone methylation-dependent mechanisms impose ligand dependency for gene activation by nuclear receptors. Cell 2007 128:505-518

37. Perillo B, Ombra MN, Bertoni A, Cuozzo C, Sacchetti S, Sasso A, Chiariotti L, Malorni A, Abbondanza C, Avvedimento EV: DNA oxidation as triggered by H3K9me2 demethylation drives estrogen-induced gene expression. Science 2008, 319:202-206.

38. Huang Y, Vasilatos SN, Boric L, Shaw PG, Davidson NE: Inhibitors of histone demethylation and histone deacetylation cooperate in regulating gene expression and inhibiting growth in human breast cancer cells. Breast 
Cancer Res Treat 2011. [Epub ahead of print]

39. Huang J, Sengupta R, Espejo AB, Lee MG, Dorsey JA, Richter M, Opravil S, Shiekhattar R, Bedford MT, Jenuwein T, Berger SL: p53 is regulated by the lysine demethylase LSD1. Nature 2007, 449:105-108.

40. Wang J, Hevi S, Kurash JK, Lei H, Gay F, Bajko J, Su H, Sun W, Chang H, Xu G, Gaudet F, Li E, Chen T: The lysine demethylase LSD1 (KDM1) is required for maintenance of global DNA methylation. Nat Genet 2009, 41:125-129.

41. Schulte JH, Lim S, Schramm A, Friedrichs N, Koster J, Versteeg R, Ora I, Pajtler K, Klein-Hitpass L, Kuhfittig-Kulle S, Metzger E, Schule R, Eggert A, Buettner R, Kirfel J: Lysine-specific demethylase 1 is strongly expressed in poorly differentiated neuroblastoma: implications for therapy. Cancer Res 2009, 69:2065-2071

42. Klose RJ, Yamane K, Bae Y, Zhang D, Erdjument-Bromage H, Tempst P, Wong J, Zhang Y: The transcriptional repressor JHDM3A demethylates trimethyl histone H3 lysine 9 and lysine 36. Nature 2006, 442:312-316.

43. Yamane K, Toumazou C, Tsukada Y, Erdjument-Bromage H, Tempst P, Wong J, Zhang Y: JHDM2A, a JmjC-containing H3K9 demethylase, facilitates transcription activation by androgen receptor. Cell 2006, 125:483-495.

44. Chen Z, Zang J, Whetstine J, Hong X, Davrazou F, Kutateladze TG, Simpson M, Mao Q, Pan CH, Dai S, Hagman J, Hansen K, Shi Y, Zhang G: Structural insights into histone demethylation by JMJD2 family members. Cell 2006, 125:691-702.

45. Yamane K, Tateishi K, RKlose RJ, Fang J, Fabrizio LA, Erdjument-Bromage H, Taylor-Papadimitriou J, Tempst P, Zhang Y: PLU-1 is an H3K4 demethylase involved in transcriptional repression and breast cancer cell proliferation. Mol Cell 2007, 25:801-812.

46. Sharma SV, Lee DY, Li B, Quinlan MP, Takahashi F, Maheswaran S, McDermott U, Azizian N, Zou L, Fischbach MA, Wong KK, Brandstetter K, Wittner B, Ramaswamy S, Classon M, Settleman J: A chromatin-mediated reversible drug-tolerant state in cancer cell subpopulations. Cell 2010, 141:69-80.

47. Wiegand KC, Shah SP, Al-Agha OM, Zhao Y, Tse K, Zeng T, Senz J, McConechy MK, Anglesio MS, Kalloger SE, Yang W, Heravi-Moussavi A, Giuliany R, Chow C, Fee J, Zayed A, Prentice L, Melnyk N, Turashvili G, Delaney AD, Madore J,Yip S, McPherson AW, Ha G, Bell L, Fereday S, Tam A, Galletta L, Tonin PN, Provencher D, Miller D, Jones SJ, Moore RA, Morin GB, Oloumi A, Boyd N, Aparicio SA, Shih le M, Mes-Masson AM, Bowtell DD, Hirst M, Gilks B, Marra MA, Huntsman DG: ARID1A mutations in endometriosis-associated ovarian carcinomas. N Engl J Med 2010, 363:1532-1543.

48. Greiner D, Bonaldi T, Eskeland R, Roemer E, Imhof A: Identification of a specific inhibitor of the histone methyltransferase SU(VAR)3-9. Nat Chem Biol 2005, 1:143-145.

49. Tan J, Yang X, Zhuang L, Jiang X, Chen W, Lee PL, Karuturi RK, Tan PB, Liu ET, Yu $\mathrm{Q}$ : Pharmacologic disruption of Polycomb-repressive complex 2-mediated gene repression selectively induces apoptosis in cancer cells. Genes Dev 2007, 21:1050-1063

50. Hamamoto R, Silva FP, Tsuge M, Nishidate T, Katagiri T, Nakamura Y, Furukawa $Y$ : Enhanced SMYD3 expression is essential for the growth of breast cancer cells. Cancer Sci 2006, 97:113-118.

51. Luo XG, Zou JN, Wang SZ, Zhang TC, Xi T: Novobiocin decreases SMYD3 expression and inhibits the migration of MDA-MB-231 human breast cancer cells. IUBMB Life 2010, 62:194-199.

52. Lee M, Wynder C, Schmidt D, McCafferty D, Shiekhattar R: Histone H3 lysine 4 demethylation is a target of nonselective antidepressive medications. Chem Biol 2006, 13:563-567.

53. Metzger E, Wissmann M, Yin N, Muller J, Schneider R, Peters A, Gunther T, Buettner R, Schule R: LSD1 demethylates repressive histone marks to promote androgen-receptor-dependent transcription. Nature 2005, 437:436-439.

54. Huang Y, Greene E, Stewart TM, Goodwin AC, Baylin SB, Woster PM, Casero Jt RA: Inhibition of lysine-specific demethylase 1 by polyamine analogues results in reexpression of aberrantly silenced genes. Proc Natl Acad Sci U S A 2007, 104:8023-8028.

55. Huang Y, Stewart TM, Wu Y, Baylin SB, Marton LJ, Perkins B, ones RJ, Woster PM Casero Jr RA: Novel oligoamine analogues inhibit lysine-specific demethylase 1 and induce reexpression of epigenetically silenced genes. Clin Cancer Res 2009, 15:7217-7228.

56. Zhu Q, Huang Y, Marton $\perp$, Woster PM, Davidson NE, Casero RA: Polyamine analogues modulate gene expression by inhibiting lysine-specific demethylase 1 (LSD1) and altering chromatin structure in human breast cancer cells. Amino Acids 2011, in press.

57. Chen Z, Zang J, Kappler J, Hong X, Crawford F, Wang Q, Lan F, Jiang C,
Whetstine J, Dai S, Hansen K, Shi Y, Zhang G: Structural basis of the recognition of a methylated histone tail by JMJD2A. Proc Nat/ Acad Sci US A 2007, 104:10818-10823.

58. Holm K, Hegardt C, Staaf J, Vallon-Christersson J, Jonsson G, Olsson H, Borg A, Ringner M: Molecular subtypes of breast cancer are associated with characteristic DNA methylation patterns. Breast Cancer Res 2010, 12:R36.

59. Pathiraja TN, Stearns $V$, Oesterreich S: Epigenetic regulation in estrogen receptor positive breast cancer - role in treatment response. J Mammary Gland Biol Neoplasia 2010, 15:35-47.

60. Catteau A, Morris JR: BRCA1 methylation: a significant role in tumour development? Semin Cancer Biol 2002, 12:359-371.

61. Esteller M, Silva JM, Dominguez G, Bonilla F, Matias-Guiu X, Lerma E, Bussaglia E, Prat J, Harkes IC, Repasky EA, Gabrielson E, Schutte M, Baylin SB, Herman JG: Promoter hypermethylation and BRCA1 inactivation in sporadic breast and ovarian tumors. J Natl Cancer Inst 2000, 92:564-569.

62. Ordway JM, Budiman MA, Korshunova Y, Maloney RK, Bedell JA, Citek RW, Bacher B, Peterson S, Rohlfing T, Hall J, Brown R, Lakey N, Doerge RW, Martienssen RA, Leon J, McPherson JD, Jeddeloh JA: Identification of novel high-frequency DNA methylation changes in breast cancer. PLoS One 2007, 2:e1314.

63. Korshunova Y, Maloney RK, Lakey N, Citek RW, Bacher B, Budiman A, Ordway JM, McCombie WR, Leon J, Jeddeloh JA, McPherson JD: Massively parallel bisulphite pyrosequencing reveals the molecular complexity of breast cancer-associated cytosine-methylation patterns obtained from tissue and serum DNA. Genome Res 2008, 18:19-29.

64. Ruike Y, Imanaka Y, Sato F, Shimizu K, Tsujimoto G: Genome-wide analysis of aberrant methylation in human breast cancer cells using methyl-DNA immunoprecipitation combined with high-throughput sequencing. BMC Genomics 2010, 25:137-148.

65. Fang F, Turcan S, Rimner A, Kaufman A, Giri D, Morris LG, Shen R, Seshan V, Mo Q, Heguy A, Baylin SB, Ahuja N, Viale A, Massague J, Norton L, Vahdat LT, Moynahan ME, Chan TA: Breast cancer methylomes establish an epigenomic foundation for metastasis. Sci Trans/ Med 2011, 3:75ra25.

66. Sproul D, Nestor C, Culley J, Dickson JH, Dixon JM, Harrison DJ, Meehan RR, Sims AH, Ramsahoye BH: Transcriptionally repressed genes become aberrantly methylated and distinguish tumors of different lineages in breast cancer. Proc Natl Acad Sci U S A 2011, 108:4364-4369.

67. International Human Epigenome Consortium [www.hec-epigenomes.org]

68. Lister R, Pelizzola M, Dowen RH, Hawkins RD, Hon G, Tonti-Filippini J, Nery JR, Lee L, Ye Z, Ngo QM, Edsall L, Antosiewicz-Bourget J, Stewart R, Ruotti V, Millar AH, Thomson JA, Ren B, Ecker JR: Human DNA methylomes at base resolution show widespread epigenomic differences. Nature 2009, 462:315-322.

69. Goren A, Ozsolak F, Shoresh N, Ku M, Adli M, Hart C, Gymrek M, Zuk O, Regev A, Milos PM, Bernstein BE: Chromatin profiling by directly sequencing small quantities of immunoprecipitated DNA. Nat Methods 2010, 7:47-49.

70. Ernst J, Kellis M: Discovery and characterization of chromatin states for systematic annotation of the human genome. Nat Biotechnol 2010, 28:817-825.

71. Bock C, Tomazou EM, Brinkman AB, Muller F, Simmer F, Gu H, Jager N, Gnirke A, Stunnenberg HG, Meissner A: Quantitative comparison of genome-wide DNA methylation mapping technologies. Nat Biotechnol 2010, 28:1106-1114.

72. Harris RA, Wang T, Coarfa C, Nagarajan RP, Hong C, Downey SL, Johnson BE, Fouse SD, Delaney A, Zhao Y, Olshen A, Ballinger T, Zhou X, Forsberg KJ, Gu J, Echipare L, O'Geen H, Lister R, Pelizzola M, Xi Y, Epstein CB, Bernstein BE, Hawkins RD, Ren B, Chung WY, Gu H, Bock C, Gnirke A, Zhang MQ, Haussler D, Ecker JR, Li W, Farnham PJ, Waterland RA, Meissner A, Marra MA, Hirst M, Milosavljevic A, Costello JF: Comparison of sequencing-based methods to profile DNA methylation and identification of monoallelic epigenetic modifications. Nat Biotechnol 2010, 28:1097-1105.

73. Dickinson LA, Dickinson CD, Kohwi-Shigematsu T: An atypical homeodomain in SATB1 promotes specific recognition of the key structural element in a matrix attachment region. J Biol Chem 1997. 272:11463-11470.

74. de Belle I, Cai S, Kohwi-Shigematsu T: The genomic sequences bound to special AT-rich sequence-binding protein 1 (SATB1) in vivo in Jurkat T cells are tightly associated with the nuclear matrix at the bases of the chromatin loops. J Cell Biol 1998, 141:335-348.

75. Alvarez JD, Yasui DH, Niida H, Joh T, Loh DY, ohwi-Shigematsu T: The MARbinding protein SATB1 orchestrates temporal and spatial expression of 
multiple genes during T-cell development. Genes Dev 2000, 14:521-535.

76. Han HJ, Russo J, Kohwi Y, Kohwi-Shigematsu T: SATB1 reprogrammes gene expression to promote breast tumour growth and metastasis. Nature 2008, 452:187-193.

77. Iorns E, Hnatyszyn HJ, Seo P, Clarke J, Ward T, Lippman M: The role of SATB1 in breast cancer pathogenesis. J Nat/ Cancer Inst 2010, 102:1284-1296.

78. Cai S, Lee CC, Kohwi-Shigematsu T: SATB1 packages densely looped, transcriptionally active chromatin for coordinated expression of cytokine genes. Nat Genet 2006, 38:1278-1288

79. Elsasser SJ, Allis CD, Lewis PW: Cancer. New epigenetic drivers of cancers. Science 2011, 331:1145-1146.
80. Roadmap Epigenomics Project [http://www.roadmapepigenomics.org/ data]

81. Milosavljevic A: Putting epigenome comparison into practice. Nat Biotechnol 2010, 28:1053-1056.

82. The Cancer Genome Atlas Data Portal [http://tcga-data.nci.nih.gov/tcga/]

doi:10.1186/bcr2925

Cite this article as: Huang Y, et al:: Epigenetics in breast cancer: what's new? Breast Cancer Research 2011, 13:225. 